\title{
IDENTIFICANDO O PERFIL DO PÚBLICO-ALVO DOS CURSOS DE GRADUAÇÃO NA MODALIDADE DE EDUCAÇÃO A DISTÂNCIA, NO BRASIL: UMAANÁLISE EXPLORATÓRIA
}

LAS CASAS, Alexandre Luzzi. Professor titular da Pontificia Universidade Católica de São Paulo, FEA, PUC-SP e doutor em Administração pela Fundação Getúlio Vargas, FGV-SP, Rua Monte Alegre, 984, São

Paulo. E-mail: alascasas@terra.com.

ALMEIDA, Keyla Priscila dos Reis de. Mestranda em Administração na Pontificia Universidade Católica de São Paulo, FEA, PUC-SP, Rua Monte Alegre, 984, São Paulo. E-mail: keylareisalmeida @ hotmail.com. VIANA, Rodrigo Bahia de Cerqueira. Mestrando em Administração na Pontificia Universidade Católica de São Paulo, FEA, PUC-SP, Rua Monte Alegre, 984, São Paulo. E-mail: viana.rodrigo@uol.com.br.

\section{Resumo}

A modalidade de educação a distância (EAD), processo de aprendizado em que parte da transmissão do conhecimento é realizado de forma remota, tem se desenvolvido rapidamente no Brasil e se configurado como uma alternativa educacional importante pelo seu potencial de inclusão social. Embora o número de matrículas e a oferta de cursos de graduação tenham crescido significativamente nos últimos anos, um problema persistente para a evolução dessa oferta é a carência de informações quantitativas e qualitativas atualizadas sobre o perfil dos alunos matriculados. Para tentar suprir esta lacuna, este artigo busca identificar as principais características desse grupo de alunos utilizando os dados do Censo de Educação Superior de 2009 e os resultados do questionário socioeconômico do Enade de 2009, para depois fornecer sugestões para a customização e melhoria dos cursos de graduação oferecidos nessa modalidade no Brasil.

PalaVras-chaVe: Educação a distância; Marketing Educacional; Segmentação mercadológica.

\begin{abstract}
Distance education(DE), a learning process where some parts of the knowledge transmission is remotely conducted , has developed fast in Brazil and has been considered an important educational alternative, due to its great potential for social inclusion. Although both the enrollment and the offer of undergraduate courses have grown significantly in recent years, a persistent problem for the enhancement of this learning alternative is the lack of quantitative and qualitative information about the student population. In order to try to fill this gap, this paper aims to identify the main specific characteristics of this group of students using data from the Higher Education Census 2009 and the results of the Socio-Economic Survey of ENADE 2009, then providing suggestions for the customization and improvement of the undergraduate courses offered via DE in Brazil.
\end{abstract}

KEYwORDs: Distance Education; Educational Marketing; Marketing segmentation. 


\section{INTRODUÇão}

Nas economias modernas, as fontes primárias de troca são crescentemente benefícios de competências especializadas (conhecimentos e capacidades aplicadas), e a fonte do crescimento econômico é a aplicação desses conhecimentos em bens e serviços (LUSCH; VARGO; TANNIRU, 2004). Como reflexo dessa nova realidade econômica, a busca por conhecimento especializado tornou-se uma das mais importantes vias para a ascensão social em muitas sociedades, inclusive a brasileira. Moraes (2010) afirma que a capacidade das nações de educarem sua população parece constituir um divisor de águas que separa o mundo moderno em diferentes categorias, de acordo com o grau de escolaridade da população de cada país. Costa (2009), utilizando os dados do Censo de Educação Superior de 2007, notou que menos de $15 \%$ dos jovens brasileiros, entre 18 e 24 anos, cursavam a universidade naquele ano. $O$ índice, considerado muito baixo para os padrões internacionais, demonstra que o ensino superior, apesar de ser tradicionalmente considerado um dos elementos-chave da mobilidade social, permanece de difícil acesso para boa parte dos jovens brasileiros, por diferentes razões, entre as quais a necessidade de conciliar o horário de trabalho e o das aulas, as dificuldades no deslocamento até a universidade e os custos envolvidos no pagamento das mensalidades.

Segundo Marinho (2010), citando dados da Unesco, quando comparado a países de renda média similar, o Brasil mostra um claro déficit educacional: por exemplo, em 2008, o Chile possuía $43 \%$ da população entre 18 e 24 anos matriculada em universidades. O reconhecimento das dificuldades de inclusão motivou diversas iniciativas governamentais na última década, como o fortalecimento de programas de financiamento estudantil (como o ProUni) e a ampliação do número de vagas nas universidades públicas. Essas iniciativas, apesar de extremamente positivas, claramente não conseguirão sanar os problemas para o acesso da população jovem à educação superior no curto prazo. Dessa forma, de acordo com Costa (2009), apesar do crescimento de
150\% no número de alunos em 10 anos (entre 1994 e 2004), estamos claramente atrasados em relação a muitos outros países emergentes.

Nesse contexto, a educação a distância (EAD) em que a maior parte do processo de aprendizado é realizada de forma remota - tem o potencial de se configurar como uma alternativa educacional interessante pelo seu grande potencial de expansão e de inclusão social, dada a flexibilidade do modelo e os seus custos mais baixos que os da educação presencial. Entretanto, os cursos de EAD só foram regulamentados no país a partir de 1996, por meio da Lei de Diretrizes de Base da Educação (Lei n. ${ }^{9}$ 9.394/1996), porém de forma semipresencial (a lei obriga as Instituições de Ensino a proverem centros presenciais para atender aos alunos na modalidade EAD, com o objetivo de garantir um melhor acompanhamento do processo educacional). Até 2005, contudo, não houve participação efetiva das universidades públicas, pois apenas naquele ano foi criado pelo Ministério da Educação, o Sistema Universidade Aberta do Brasil (UAB), sistema integrado por universidades públicas e que busca oferecer cursos em diversos níveis (desde especializações lato sensu à graduação e pósgraduação stricto sensu) por meio do uso da EAD.

Apesar de decorridos 15 anos desde a regulamentação dos cursos superiores a distância no Brasil, ainda existem muitas indicações de que o reconhecimento da validade dessa modalidade educacional não é consensual. Permanece acalorado o debate entre os partidários da exclusão dos cursos de graduação via $\mathrm{EAD}$ e os estudantes matriculados em cursos nesta modalidade. Entende-se que as resistências de alguns educadores e profissionais merecem sem dúvida ser consideradas seriamente, uma vez que os temores que motivaram as críticas poderão se justificar nos próximos anos, com a popularização da EAD e a expansão da oferta de cursos de qualidade questionável. Caberá ao MEC acompanhar as Instituições de Ensino Superior (IES) e exigir que estas executem melhoramentos contínuos e sanem os problemas observados. Por outro lado, é factível supor que diversos problemas já detectados no ensino 
superior presencial não serão resolvidos pela EAD. Por exemplo, a falta de preparo de parte dos alunos que ingressam no ensino superior (dado o seu fraco desempenho no ensino médio) poderá ser um impedimento para que consigam ter sucesso na $\mathrm{EAD}$, uma vez que este exige mais disciplina e algum grau de autodidatismo.

Contudo, há que se reconhecer que existe certa dose de preconceito nas críticas. O ensino a distância, apesar de certamente sujeito a problemas de qualidade (como, aliás, qualquer tipo de ensino), impõe em geral maior planejamento que o ensino presencial, em que há maior possibilidade de improvisação. Como afirma o professor Moran (2007, p.2), a própria experiência de criação de material para cursos EAD pode se refletir numa melhor preparação de cursos presenciais. $\mathrm{O}$ autor afirma, baseado em sua experiência, que frequentemente os professores envolvidos na organização de atividades a distância verificam que estas exigem planejamento, dedicação, comunicação e avaliação bem executados; caso contrário, os alunos se desmotivam e desaparecem.

Esses mesmos professores, ao voltar para as salas de aula presenciais, costumam ter uma sensação de estranhamento, de que no presencial falta algo; de que o planejamento é muito menos rigoroso, que as atividades em sala são muito menos previstas, que o material poderia ser mais adequado e que a avaliação é decidida, muitas vezes, ao sabor dos acontecimentos. Professores e alunos, ao ter acesso a bons materiais a distância, costumam trazê-los também para a sala de aula presencial e isso vem contribuindo para a diminuição da separação que ainda há entre os que fazem cursos a distância e os presenciais, nas universidades. (MORAN, 2007, p. 2).

Em resumo, a questão da manutenção da qualidade nos cursos de graduação EAD é complexa e depende de um esforço educacional intenso para a criação de material didático e condições tecnológicas apropriadas. Nesse aspecto, Prata (2003) propõe umframework para a avaliação da aprendizagem a distância com diversos módulos distintos, enfocando diversos aspectos (por exemplo, Autoavaliação e Reflexões do aluno, Planejamento das atividades, Avaliação do curso, etc.). Restam poucas dúvidas de que, quando bem executado, a EAD pode realmente proporcionar bons resultados como evidenciam muitos casos em países que já utilizam esta forma de ensino há anos, como os EUA e a Inglaterra. Os resultados do Exame Nacional de Desempenho dos Estudantes - Enade, por outro lado, parecem, até agora, promissores: têm indicado que a performance dos alunos na modalidade EAD é bastante similar à dos alunos da modalidade presencial e até mesmo superior, em algumas áreas. Por exemplo, no Enade 2008, a avaliação dos alunos que ingressaram em cursos superiores na modalidade $E A D$ revelou que estes obtiveram melhores resultados em 9 das 13 áreas avaliadas (ABED, 2008), em comparação aos que fazem o mesmo curso na modalidade presencial.

Este artigo busca identificar o público-alvo dos cursos de graduação na modalidade de Educação a Distância (EAD) no Brasil, por meio de uma comparação do perfil dos alunos matriculados em cursos de graduação na modalidade EAD e dos matriculados em cursos de graduação na modalidade presencial. Buscamos, através de uma análise quantitativa, atualizar e enriquecer as conclusões de Ristoff (2007), que, já em 2007, apontava que os alunos de EAD tinham um perfil bastante distinto dos presenciais. O objetivo final é que esta pesquisa possa trazer luz sobre as necessidades específicas desses alunos, de modo que as IES possam aprimorar sua proposta educacional na modalidade EAD por meio da customização dos cursos, utilizando estas informações.

\section{REVISÃO DA LITERATURA}

Diversos estudos dedicam-se a explorar as razões que levam os alunos a optar por esta forma EAD, analisando as vantagens e desvantagens desta metodologia de ensino (FILATRO, 2004; MEYEN et al., 2006), a elaboração de um framework tecnológico para EAD (CRUZ; MORAES; BARCIA, 
1998; FILATRO, 2004; CHRISTENSEN; HORN; JOHNSON, 2009), além de abordar casos de sucesso e fracasso (PRETI, 2009).

Por outro, lado Meyen et al. (2006) já declaravam que haveria um gap nas pesquisas relacionadas à EAD, pois as soluções de $e$-learning apenas poderiam ser analisadas tendo em vista as características especiais (por exemplo, socioeconômica) de cada grupo de alunos, o que determinaria as condições em que se dá o seu aprendizado. Assim, além de analisar essas soluções e os resultados obtidos, segundo os autores, caberia entender as necessidades específicas dos alunos, pois uma proposta educacional via EAD poderia ser bastante efetiva num grupo de alunos (por exemplo, profissionais experientes e com alta renda, realizando cursos de pósgraduação a distância), mas ineficiente e pouco atraente para outros grupos, como jovens adultos que cursam cursos de graduação via EAD.

Há, contudo, relativamente poucos estudos que exploram o perfil dos alunos de graduação via EAD no Brasil, como o de Ristoff (2007). Assim, segundo Preti (2009), muitas IES que estão lançando cursos de graduação via EAD carecem de informações para a customização da oferta educacional, através do entendimento do público-alvo de cada curso e das suas necessidades. Considerando-se que muitos autores corroboram o conceito de Marketing como um processo social, por meio do qual pessoas e grupos de pessoas obtêm aquilo que necessitam com a livre negociação de produtos e serviços de valor (KOTLER; KELLER, 2006, p. 195, GUMMESON, 1999, p. 32 ), conclui-se logicamente que um melhor conhecimento mercadológico seria crucial para as IES lançarem cursos de graduação via EAD. Essa lacuna parece, no entanto, ser mais grave nos cursos via EAD, devido às características específicas desta modalidade.

Preti (2009), por exemplo, afirmava que a EAD, por ser essencialmente mediada e haver uma distância física entre professor e aluno, se constitui numa modalidade de estudo individualizado e independente, em que se reconhece a capacidade do estudante de construir seu caminho, seu conhecimento por ele mesmo, de se tornar autodidata, ator e autor de suas práticas e reflexões. Assim, os cursos via EAD deveriam oferecer suportes que viabilizeme incentivem a autonomia dos estudantes. A tecnologia, mais que apenas comunicar unidirecionalmente o conteúdo, deveria, portanto, possibilitar a interação, buscando estabelecer relações dialogais, criativas, críticas e participativas durante o processo educativo.

\section{Metodologia}

Entende-se que, para melhor atender a um públicoalvo, as empresas necessitam de informações relevantes sobre seus potenciais clientes. Uma possibilidade para o entendimento do público-alvo seria realizar uma pesquisa quantitativa primária, buscando entender o perfil dos alunos matriculados. Essa pesquisa, no entanto, se revelou de difícil execução: os cursos na modalidade EAD atendem a um público cuja localização é muito variada (por exemplo, algumas universidades provêm cursos em mais de 400 municípios brasileiros). Optou-se, portanto, pela utilização de dados secundários contidos no Censo do Ensino Superior de 2009 e nos resultados do questionário socioeconômico do Enade de 2009. Essas informações estavam disponíveis no site do Instituto Nacional de Pesquisas Educacionais (Inep), vinculado ao Ministério da Educação.

Para entender o público-alvo dos cursos de graduação na modalidade EAD, foi necessário analisar separadamente cada uma dessas fontes, buscando obter as diferenças entre o perfil dos estudantes de cursos nesta modalidade e os da modalidade presencial.

Utilizando o software estatístico SPSS, procedeuse a análise inicialmente dos dados do Censo do Ensino Superior (2009). Deste censo constam dados referentes a uma amostra de quase 7 milhões de alunos - 14,4\% eram estudantes na modalidade EAD e $85,6 \%$ eram alunos na modalidade presencial. Compararam-se os alunos dessas modalidades em relação à média, mediana, frequência relativa e dispersão (variância e desvio padrão) daquela que se considerou como sendo a possível característica-chave para distinguir ambos os perfis: a idade do aluno. Essa comparação visou 
verificar a hipótese já levantada por outros autores, como Ristoff (2007), de que o aluno na modalidade EAD é, em média, mais velho que o aluno da modalidade presencial e, além disso, possui perfil socioeconômico distinto do aluno presencial, com menor renda média.

\section{Resultados}

A análise conjunta dessas fontes revelou o perfil dos alunos de EAD, trazendo insights potencialmente interessantes sobre o público-alvo. Ao analisar a idade média dos alunos, em ambas as modalidades, a conclusão aqui extraída confirma a de Ristoff (2007): os alunos de EAD são em média mais velhos que os alunos presenciais. $\mathrm{O}$ quadro a seguir mostra que os alunos na modalidade EAD são em média 7,43 anos mais velhos que os alunos na modalidade presencial. Essa diferença foi considerada como sendo extremamente significativa para traçar o perfil dos alunos de EAD.

\begin{tabular}{|l|c|c|c|c|c|}
\hline Modalidade & Idade Média & Desvio Padrão & Variância & $\begin{array}{c}\text { Número de } \\
\text { alunos }\end{array}$ & \% do Total \\
\hline Presencial & 25,91 & 7,378 & 54,441 & 5.977 .207 & $85,6 \%$ \\
\hline EAD & 33,34 & 9,316 & 86,790 & 1.004 .811 & $14,4 \%$ \\
\hline Total & 26,98 & 8,118 & 65,895 & $6.982,018$ & $100 \%$ \\
\hline
\end{tabular}

Quadro 1 - Comparação entre a idade média dos alunos de educação presencial e a distância.

Fonte: Elaborado pelos autores.

$O$ fato de o aluno na modalidade EAD ser marcantemente mais velho provavelmente se traduzirá numa diferença de interesses significativa entre os grupos, uma vez que alunos mais jovens tendem a ter menos responsabilidades e encargos que alunos mais velhos, devido ao fato de que muitos desses últimos já podem ter constituído família e estar inseridos no mercado de trabalho. Esse "atraso" no ingresso no ensino superior muito provavelmente está associado à alta evasão verificada no ensino médio. Barbosa Filho e Pessoa (2011) mostram que, apesar de 96\% dos alunos entre 5 e 14 anos estarem matriculados, este percentual cai para apenas $76 \%$ para os alunos entre 15 e 19 anos. Ainda segundo os autores, "há sinais claros de que parte significativa do abandono escolar não se deve à necessidade de o aluno trabalhar".

Ocorre que, abandonando o ensino médio, seja por desinteresse ou falta de recursos, esses alunos inevitavelmente entrarão mais tarde na universidade muito provavelmente numa idade em que a vida já lhes cobra outras responsabilidades (como a de sustentar outras pessoas). Assim, exatamente por ter menos tempo a perder, pode-se dizer que o aluno de EAD possui objetivos muito mais imediatistas, buscando formar-se num curso superior que claramente lhe permita progredir no mercado de trabalho, no qual já estão provavelmente inseridos. Os gráficos a seguir mostram claramente a diferença na composição etária dos grupos presencial e a distância, respectivamente. 


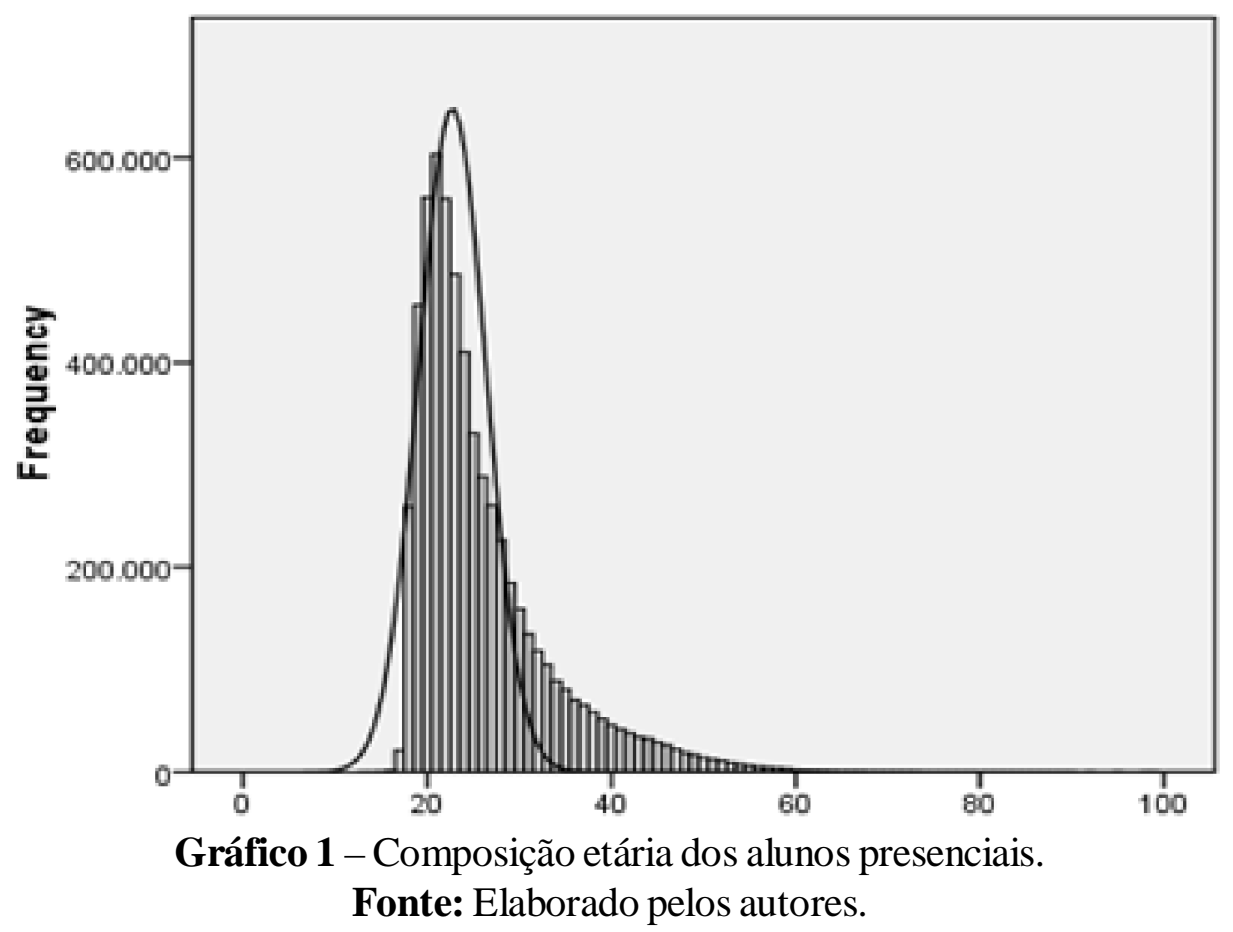

O Gráfico 1, que mostra o perfil dos alunos presenciais, demonstra que os alunos presenciais são mais jovens e possuem menor dispersão do que os alunos de EAD (Gráfico 2). Já o Gráfico 2, de forma mais alongada e deslocada para a direita, evidencia a maior dispersão de idades e uma maior frequência de alunos com mais de 40 anos.

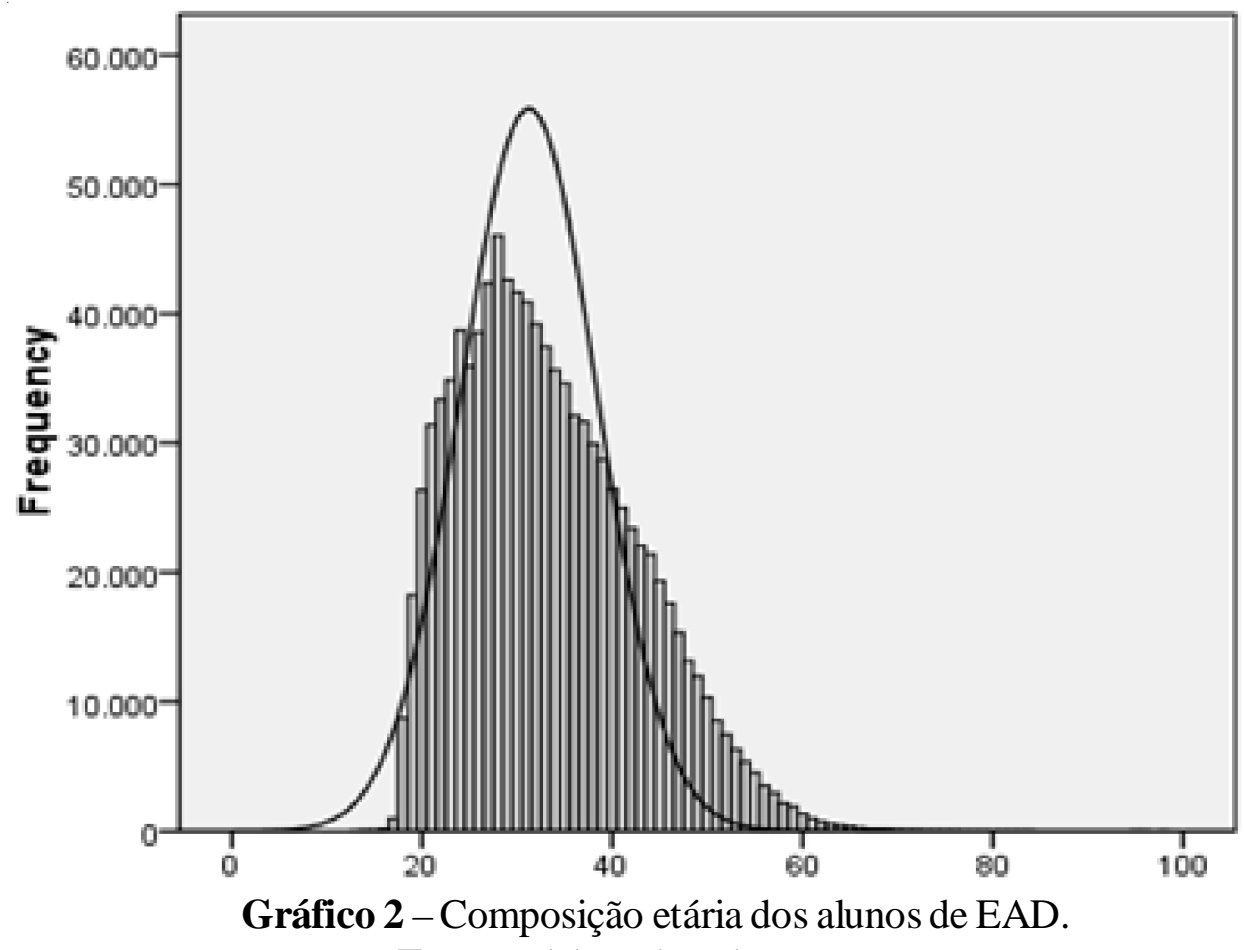

Fonte: Elaborado pelos autores. 
Efetivamente, dado o maior desvio padrão e variância verificados no grupo de alunos de EAD, constata-se que este grupo possui maior dispersão, isto é, constitui-se num grupo mais heterogêneo que o dos alunos presenciais.
Subdividindo os alunos de EAD por quartis (conforme quadro abaixo) e utilizando-se como parâmetro a faixa etária, verifica-se que alunos com mais de 40 anos representavam $25 \%$ dos alunos de EAD, em 2009.

\begin{tabular}{|c|c|c|c|}
\hline Modalidade & $\mathbf{1 .}^{\mathbf{0}}$ Quartil & $\mathbf{2 .}^{\mathbf{}}$ Quartil & 3. $^{\mathbf{Q}}$ Quartil \\
\hline Presencial & Até 21 anos & Até 24 anos & Até 29 aos \\
\hline EAD & Até 26 anos & Até 32 anos & Até 40 anos \\
\hline
\end{tabular}

Quadro 2 - Idade média por quartis.

Fonte: Elaborado pelos autores.

Por outro lado, verifica-se que $25 \%$ desses alunos de EAD tinham menos que 26 anos, em 2009. Haveria diferenças socioeconômicas entre o primeiro (até 26 anos) e último quartis (a partir de 40 anos), dada a grande diferença de idade verificada entre esses quartis?

Considerou-se que os principais indicadores diretos do perfil socioeconômico contidos no dado do censo seriam a presença de apoio social, financiamento estudantil e ingresso no ensino superior por meio de reserva de vagas. Analisando-se esses dados apenas para os alunos EAD, não foi possível identificar diferenças significativas estatisticamente para o perfil socioeconômico baseado apenas na idade dos alunos. Assim, o resultado parece confirmar que o grupo de alunos de EAD tem um perfil socioeconômico similar, independentemente de sua idade. Contudo, comparando-se o grupo de alunos de EAD e os presenciais, nota-se que os primeiros têm maior percentual de apoio social (moradia, transporte, material didático e bolsa trabalho) que os demais.

\begin{tabular}{|c|c|c|c|}
\hline Modalidade & Apoio Social & $\begin{array}{c}\text { Financiamento } \\
\text { Estudantil }\end{array}$ & $\begin{array}{c}\text { Ingresso por Reserva } \\
\text { de Vagas }\end{array}$ \\
\hline Presencial & $4 \%$ & $18 \%$ & $1 \%$ \\
\hline EAD & $18 \%$ & $7 \%$ & $1 \%$ \\
\hline
\end{tabular}

Quadro 3 - Fatores socioeconômicos.

Fonte: Elaborado pelos autores.

Embora a maior presença de alunos com apoio social (ou seja, que recebem ajuda de algum programa social) possa indicar que o grupo de alunos de EAD tenha menor renda média que os alunos presenciais, e como a renda pessoal e familiar não consta do censo, esta análise não é conclusiva, ainda que existam indicações de que o aluno de EAD é mais desfavorecido economicamente, como afirma Ristoff (2007) em seu estudo. Entretanto, baseando-se nos dados do PNAD 2009, pode-se afirmar que os jovens das classes C/D ainda são a grande maioria da população brasileira em idade escolar. Nesse enorme mercado de jovens (e jovens adultos), existe uma importante parcela que se encontra defasada nos estudos (uma vez que a escolaridade média da classe $\mathrm{C}$, segundo o PNAD 2009, é cerca de sete anos menor que a dos integrantes das classes A/B). Como a idade média dos alunos de EAD é de 32 anos, muitos dos jovens das classes $\mathrm{C} /$ D nesta idade já provavelmente estarão integrados ao mercado de trabalho e terão constituído sua família, o que dificultaria a sua adesão a cursos presenciais, e que os levaria a optar pela graduação a distância. 
Por outro lado, quanto ao perfil de gênero (Quadro 4), nota-se uma interessante característica do público dos cursos EAD: existem duas vezes mais mulheres do que homens.

\begin{tabular}{|c|c|c|}
\hline Modalidade & Masculino & Feminino \\
\hline Presencial & $45,6 \%$ & $54,4 \%$ \\
\hline EAD & $31,8 \%$ & $68,2 \%$ \\
\hline
\end{tabular}

Quadro 4-Gênero.

Fonte: Elaborado pelos autores.

Essa tendência pode estar influenciada pelo fato de grande parte dos cursos de EAD oferecidos atualmente serem voltados às Ciências Humanas e Sociais (mais de $90 \%$ dos cursos estão assim classificados, segundo o Anuário de EAD). Nesses cursos, tradicionalmente, se nota uma maior presença de mulheres matriculadas que de homens (que são majoritários apenas nas Engenharias e Ciências Exatas). Por outro lado, Rocha da Silva, Vendramini e Lopes (2010) mostraram que, analisando-se os dados socioeconômicos e de gênero do Enade de 2005, o público feminino matriculado no ensino superior brasileiro tinha renda familiar mais baixa que a do público masculino. Segundo essas autoras, $37 \%$ das mulheres que frequentavam curso superior possuíam renda familiar menor que três salários mínimos, ante cerca de $20 \%$ dos homens. Finalmente, analisou-se o fator étnico ou racial, considerando-se o grupo étnico como um fator autodeclarado pelos alunos. Os dados são, entretanto, inconclusivos, pois há um grande percentual de alunos cuja origem étnica não estava disponível ou não foi declarada ao censo.

Concluiu-se, por meio desta análise, que o aluno da modalidade EAD é, em média, cerca de oito anos mais velho e, em sua grande maioria $(68,2 \%)$, do sexo feminino, além de ter menor renda média do que o aluno presencial. Essas conclusões estão alinhadas com as conclusões dos estudos de Ristoff (2007), mas adicionam informações, sobretudo por destacarem as marcantes diferenças em gênero e idade média.

Assim, mesmo confirmando as afirmações de Ristoff (2007) de que este grupo de alunos seria em média mais velho, mais pobre e menos branco, caberia a nós acrescentar elementos inéditos ao perfil: estes alunos também seriam majoritariamente do sexo feminino e com idade média de 32 anos. Portanto, é provável que uma parcela importante deles já tenha constituído família (dado serem muito mais velhos), o que leva à conclusão de que muitos provavelmente conciliariam uma dupla ou tripla jornada (trabalho, estudos em casa e cuidados com os filhos).

Com base nessas conclusões, quais seriam as necessidades específicas do aluno em questão e como adaptar a oferta educacional de cursos de graduação emEAD, considerando que há uma marcante diferença entre o perfil dos alunos de EAD e o dos alunos presenciais? Como essas necessidades afetariam as diversas etapas do processo educacional para os alunos de EAD?

Segundo Preti (2009), há mandatoriamente duas etapas a serem desenvolvidas em cada disciplina ministrada nos cursos de graduação via EAD no Brasil. Inicialmente, haveria um primeiro momento a distância, em que o aluno assiste às aulas remotamente (por exemplo, pela internet) e faz os exercícios em casa. Em seguida, haveria um segundo momento, presencial, em que o aluno teria que se deslocar para um centro de estudos e discutir o material estudado e os resultados das aulas (exercícios, sínteses) com seus colegas de turma e um tutor. Ainda segundo Preti (2009), o tutor seria um dos elementos-chave para o sucesso do curso e teria um papel fundamental no processo de aprendizagem, pois é através dele que se garante a interação personalizada e se viabiliza uma articulação entre os elementos do processo, necessária à consecução dos objetivos propostos.

Como se identificou neste presente estudo, o aluno de EAD, em muitos casos, concilia o estudo com as atividades do trabalho e da família, e seria interessante provavelmente tornar mais acessível o tutor, seja realizando as reuniões presenciais em locais mais próximos à residência do aluno (por meio de uma estratégia de distribuição geográfica desses centros), seja fornecendo transporte escolar aos centros de estudos. Por outro lado, como se trata de um público 
em grande parte do sexo feminino e muito possivelmente com filhos, o oferecimento de convênios com creches nos dias das reuniões presenciais seria possivelmente um recurso interessante.

Além disso, o tutor poderia ser treinado para desenvolver características de empatia e afinidade com esse grupo de alunos, de forma a aumentar a interação e diminuir o absenteísmo dos alunos às reuniões presenciais. Uma das formas possíveis para aumentar a interação seria recrutar tutores entre exalunos do ensino EAD e que compreendam suas necessidades (por as terem vivenciado), por outro lado fornecendo exemplos que reforcem a autoconfiança dos alunos e seu autodidatismo. Dessa forma, Preti (2009) afirma que cada instituição deveria buscar construir seu modelo tutorial de forma bastante cuidadosa, visando atender às necessidades específicas do seu público-alvo, uma vez que este é um dos principais fatores de sucesso. Por outro lado, ainda segundo o autor, é muito importante que todos os passos e etapas dos cursos oferecidos sejam planejados pela equipe de coordenação com antecedência e que os alunos sejam informados dos detalhes práticos desde o início de seu percurso, por meio de um Manual do Estudante.

Finalmente, a utilização de tecnologia que facilite a interatividade é fortemente indicada, inclusive com o fornecimento de equipamentos para os alunos (tais como tablets ou computadores pessoais). Contudo, para que seja efetivo qualquer aprendizado utilizando computador, a tecnologia, segundo Christensen, Horn e Johnson (2009, p. 99), deve ser centrada no aluno, ou seja, a metodologia pedagógica, o software e os recursos didáticos informatizados têm que ser cuidadosamente testados, utilizando-se amostras de alunos com o perfil identificado para que se verifique sua adequação pedagógica e se possam realizar gradativamente as melhorias necessárias no material didático e nos recursos tecnológicos disponibilizados (como por exemplo, a interface e o software para acesso remoto, que deve ser bastante simples e amigável, não requerendo configurações adicionais por parte do aluno).

\section{Considerações Finais}

A Educação a Distância, segundo Daniel e Kanwar (2008), surgiu como uma alternativa educacional para atingir novos estudantes e suportar melhor a expansão da acessibilidade ao ensino, com menor custo e menor perda de qualidade no processo de democratização da educação. Segundo os autores, a expansão do acesso à educação presencial em geral ocorre em detrimento da qualidade. No entanto, com a EAD esse trade-off não necessariamente se confirmaria, pois, quando bem planejada e executada, esta modalidade de ensino teria a possibilidade de expandir-se sem que a qualidade sofresse tanto.

O Brasil viveu recentemente a democratização do acesso ao ensino fundamental e expandiu fortemente as matrículas no ensino superior (embora com certo atraso em relação aos países vizinhos, como Argentina e Chile). Contudo, os resultados obtidos nas avaliações dos alunos indicam que há um grande caminho a percorrer até que se consiga atingir uma performance aceitável. AEAD pode tornar-se um ponto positivo nesse cenário, uma vez que as avaliações do Enade têm sido supreendentemente promissoras.

Moran (2007), por outro lado, explicita as profundas mudanças que a $\mathrm{EAD}$ pode causar na forma tradicional de ensino, alterando o conceito de presença e distância, no processo de aprendizado. Dessa forma, haveria uma aproximação sem precedentes entre os cursos presenciais e os a distância, sendo uma tendência geral a forte flexibilização do processo educacional, com mais independência em relação ao tempo e espaço. Por outro lado, Christensen, Horn e Johnson (2009, p. 107) concluem que quatro grandes forças podem impulsionar a substituição do professor presencial pelo ensino semipresencial via EAD: o contínuo aperfeiçoamento das tecnologias envolvidas, a crescente customização e melhoria dos programas de ensino via EAD (uma vez que estes programas estarão sempre sujeitos à avaliação governamental e dos alunos), a crescente escassez de bons professores frente à enorme demanda educacional e a redução gradual dos custos de aprendizado.

Essas previsões têm-se confirmado no Brasil, uma 
vez que estamos observando um crescimento acelerado da oferta de cursos e do número de matrículas em cursos via EAD. Contudo, é vital para as IES identificar o público a que se destinam esses cursos, pois se trata de um público com demandas específicas.

De acordo com esta pesquisa, foi possível concluir que o público para os cursos de graduação na modalidade EAD é composto majoritariamente pela população de jovens adultos (média de idade de 32 anos), de renda baixa ou média, do sexo feminino e que concluíram com certo atraso o segundo grau, buscando na modalidade EAD uma forma de compensar o tempo perdido e progredir socialmente. Os resultados obtidos permitem ainda confirmar a maioria das conclusões de Ristoff (2007), que já apontavam para um perfil socioeconômico diferente dos alunos da modalidade presencial.

Estas conclusões podem constituir um ponto de partida importante para o aprimoramento de uma estratégia de Marketing Educacional nas IES, focada nas necessidades do público-alvo desses cursos. Contudo, para que as Instituições de Ensino Superior (IES) privadas possam usufruir das vantagens competitivas relativas à diferenciação da oferta em EAD. Finalmente, apesar da identificação das principais características do perfil desse público ser um passo inicial para a criação de uma oferta educacional diferenciada, o entendimento mais detalhado das necessidades de um grupo tão heterogêneo de alunos requer, por parte das IES, pesquisas adicionais e mais detalhadas. Assim, como o presente estudo fez uso apenas de dados secundários, é possível que, para melhor compreender como disponibilizar uma oferta de cursos mais atrativa, seja necessário realizar o aprofundamento das informações sobre esse público por meio da realização de uma pesquisa de dados primários, utilizando amostras de alunos de EAD. Entre as investigações que podem ser realizadas nessas pesquisas adicionais, caberia entender as razões da grande preponderância do sexo feminino nos cursos de graduação via EAD. Isso se deveria ao fato de que as mulheres têm menos tempo disponível para fazer uma faculdade presencial (por exemplo, porque são mães e cumprem dupla jornada de afazeres) ou isso se deveria ao fato de a maior parte dos cursos de EAD atualmente disponíveis serem voltados às ciências humanas, o que acaba por atrair mais mulheres que homens?

Por outro lado, neste artigo conseguimos identificar que os alunos de EAD têm menor renda média que os alunos presenciais. Mas quão mais baixa é essa renda? Qual o nível socioeconômico (classe social) dos alunos de EAD? Quais dificuldades e necessidades especiais estariam associadas às limitações de renda e ao ingresso tardio no ensino superior?

Essa segmentação mais aprofundada se constituiria numa interessante aplicação do Marketing Educacional, que, de acordo com a definição de Manes (2005), deveria conduzir um processo de investigação de necessidades sociais tendente a desenvolver e levar a cabo programas educativos que as satisfaçam, produzindo um crescimento integral do indivíduo.

\section{REFERÊNCIAS}

ABED. Anuário Brasileiro Estatístico de Educação Aberta e a Distância, 2008.

ASSOCIAÇÃO BRASILEIRA DOS ESTUDANTES DE EDUCAÇÃO A DISTÂNCIA. Pesquisa Estudantes EAD 2010. Disponível em: < http://www.estudantes EAD.org.br/>. Acesso em: 5 maio 2011.

BARBOSA FILHO, Fernando; PESSOA, Samuel. Metas da Educação para a próxima década. In: GIAMBIAGI, Fabio; PORTO, Claudio. 2022:

Propostas para um Brasil melhor no ano do bicentenário. Rio de Janeiro: Campus, 2011, p. 312.

BRASIL. Ministério da Educação. Universidade Aberta do Brasil. Disponível em: <www.uab.capes.gov.br>. Acesso em: 12 ago. 2011.

CHRISTENSEN, Clayton; HORN, Michael B.; 
Identificando o perfil do público-alvo dos cursos...

JOHNSON, Curtis W. Inovação na sala de aula: como a inovação de ruptura muda a forma de aprender. Porto Alegre: Bookman, 2009.

COBRA, Marcos; BRAGA, Ryon. Marketing educacional. 2004. Disponível em: <http:// books.google.co.uk/books?hl=en\&lr=\&id=J MhYGgRPSgAC\&oi=fnd\&pg=PA1\&ots=Jg5VAdbv9\&sig=jUNnFHf5jLFZzbP9JgEIV1LYkH8\#v= onepage \&q\&f=false $>$. Acesso em: 10 maio 2011.

\section{COSTA, Gilberto. Número de estudantes} universitários é de quase cinco milhões. Fev. 2009. Disponível em: <http://www.anj.org.br/ jornaleeducacao/noticias/numero-de-estudantesuniversitarios-e-de-quase-cinco-milhoes/>. Acesso em: 5 out. 2010.

CRUZ, Dulce Marcia; MORAES, Marialice; BARCIA, Ricardo. Tele-learning and distance learning re-engineering process. 1998. Disponível em: <http://ineerweb.osanet.cz/Events/ ICEE1998/ICEE/papers/433.pdf> . Acesso em:1 jun. 2012.

DANIEL, John; KANWAR, Asha. The right to education: a model for making higher education equally accessible to all on the basis of merit. Asian Journal of Distance, 2008. Disponível em: <http:// www.col.org/SiteCollectionDocuments/ KawachiUDHRFinal.pdf >. Acesso em: 25 ago. 2011.

FILATRO, Andréa. Design instrucional contextualizado: educação e tecnologia. São Paulo: Senac, 2004.

FINGER, Almeri Paulo. (Org.). Gestão de universidades: novas abordagens. Curitiba: Champagnat, 1997.

GUMMESON, Evert. Marketing de relacionamento total. Porto Alegre:
Bookman,1999.

INEP. Censo do Ensino Superior 2009.

Disponível em: 〈www.inep.gov.br >. Acesso em: 22 ago. 2011.

INEP. Resultados do ENADE 2008. Disponível em: <http://portal.inep.gov.br/planilhas-enade>. Acesso em: 21 ago. 2011.

KOTLER, Philip; KELLER, Kevin. Administração de Marketing. 12. ed. São Paulo: Prentice Hall, 2006.

LUSCH, Robert; VARGO, Stephen L.; TANNIRU, Mohan. Evolving to a new dominant logic for marketing. Journal of the Academy of Marketing Science, 2004, v. 68, p.1-17.

MANES, Juan Manuel. Marketing para Instituciones Educativas. Buenos Aires: Granica, 2005.

MARINHO, Luis Alberto. Em seis anos quantidade de universitários subiu $46 \%$ no Brasil. Agosto, 2010. Disponívelem: <www.bluebus.com.br/show/1/98400/>. Acesso em: 20 maio 2011.

MEYEN, Edward et al. e-Learning: a research construct. University of Kansas, 2006.

MORAES, R. C. C. Educação a distância e ensino superior: introdução didática a um tema polêmico. São Paulo: Senac, 2010.

MORAN, José Manoel. Avaliação do ensino superior a distância no Brasil. 2007. Faculdade de Educação/USP. Disponível em: <www.eca.usp.br/prof/moran/avaliacao.htm>. Acesso em: 30 jul. 2011.

PNAD. Pesquisa Nacional de Amostra por 
Domicílios, 2009. Ministério da Fazenda (Secretaria de Política Econômica). Disponível em: <http:// www.fazenda.gov.br>. Acesso em: 30 jul. 2011.

PRATA, David N. Estratégias para o desenvolvimento de um framework de avaliação da aprendizagem a distância, SBIE, 2003.

Disponível em: <http://ceie-sbc.educacao.ws/pub/ index.php/sbie/article/view/245>. Acesso em: 23 maio 2012.

PRETI, Oreste. Educação a distância: uma prática educativa mediadora e mediatizada, 2009. Disponível em: <http://www.nead.ufmt.br/ index.asp?pg=7>. Acesso em: 12 abr. 2012.

RISTOFF, Dilvo. A trajetória dos cursos de graduação a distância, 2007. Ministério da Eduacação. Disponívelem: <http://

www.mec.gov.br>. Acesso em: 29 jul. 2011.

ROCHADASILVA, Maria Cristina;

VENDRAMINI, Claudette Maria Medeiros;

LOPES, Fernanda Luzia. Diferenças entre gênero e perfil sócio-econômico no Exame Nacional de Desempenho do Estudante. Revista da Avaliação da Educação Superior, v. 15, n. 3, Sorocaba, nov. 2010, p. 185-202. 